\title{
AVALIAÇÃO DA ATIVIDADE LOCOMOTORA APÓS INDUÇÃO LOCAL DE DESMIELINIZAÇÃO TÓXICA NO TRONCO ENCEFÁLICO DE RATOS WISTAR
}

\author{
Eduardo Fernandes Bondan', Maria Anete Lallo', Heloísa Orsini', \\ Henri Levi Donnaruma Bentubo', Ângela Yazbek', Daclê Juliani Macrini', \\ Maria Martha Bernardi', Dominguita Luhers Graça²
}

\begin{abstract}
RESUMO - Lesões desmielinizantes induzidas pelo gliotóxico brometo de etídio (BE) têm sido estudadas com o objetivo de permitir a compreensão do limitado processo de reparo mielínico no sistema nevoso central, bem como avaliar estratégias terapêuticas no sentido de acelerar a reconstrução das bainhas de mielina perdidas. Muito embora estudos eletrofisiológicos correlacionando situações de desmielinização e remielinização experimental sejam bem estabelecidos, os efeitos comportamentais não têm sido adequadamente investigados. Neste estudo, foram analisadas ultra-estruturalmente as lesões desmielinizantes e a atividade locomotora de ratos submetidos à indução focal de desmielinização pelo modelo do BE na superfície ventral do tronco encefálico, mediante observação de sua movimentação e controle motor durante a travessia de uma trave elevada de madeira (beam walking test). Foi observada a ocorrência de deficiências locomotoras até 31 dias pós-injeção de $B E$, constatando-se ainda que a subseqüente remielinização estava relacionada com o retorno da função perdida.
\end{abstract}

PALAVRAS-CHAVE: brometo de etídio, desmielinização, ratos, remielinização, teste da passarela elevada.

\begin{abstract}
Evaluation of locomotor activity after a local induction of toxic demyelination in the brainstem of Wistar rats

ABSTRACT - Ethidium-bromide (EB) - induced lesions have been used to investigate the incomplete remyelination in the central nervous system, as well as to evaluate therapeutic strategies to accelerate the reconstruction of the lost myelin sheaths. Although many electrophysiologic studies were perf o rmed in situations of experimental demyelination and remyelination, their behavioural effects have not been properly analyzed. In this study, we investigated ultrastructurally the EB - demyelinating lesions as well as the locomotor activity of rats during the beam walking test after a focal induction of demyelination using the EB model in the ventral surface of the brainstem. It was observed the occurrence of locomotor deficits until 31 days post-injection, as well as that subsequent remyelination was related to the re $\mathrm{u}$ rn of the lost function.
\end{abstract}

KEY WORDS: beam walking test, demyelination, ethidium bromide, rats, remyelination.

Diversos estudos acerca da desmielinização e da remielinização no sistema nervos central (SNC) têm sido empreendidos baseados no emprego do brometo de etídio (BE), uma droga intercalante gliotóxi$\mathrm{Ca}^{1-14}$. Neste modelo, observa-se o desaparecimento oligodendroglial e astrocitário, com conseqüente perda primária das bainhas de mielina, bem como ruptura da membrana limitante glial e da barreira hematoencefálica. A ausência dos processos astrocitários em muitas áreas de lesão induzida pelo BE permite a entrada de linfócitos, de células meníngeas infiltrantes e de células de Schwann, as últimas acabando por contribuir para o reparo mielínico central ${ }^{8,10}$. A remielinização das lesões desmielinizantes tem sido obtida com sucesso através da transplantação de células gliais ${ }^{15,16}$, sugerindo a possibilidade de repa ro das lesões observadas em doenças como a esclerose múltipla dos seres humanos e a cinomose dos cães com o uso de enxertos de células mielinogênicas. No entanto, antes que sua aplicação clínica possa ser contemplada, as conseqüências funcionais da desmielinização e da remielinização espontânea

'Universidade Paulista (UNIP), São Paulo, Brasil; ${ }^{2}$ Departamento de Patologia, Universidade Federal de Santa Maria (UFSM), Santa Maria, Brasil.

Recebido 24 Outubro 2005. Aceito 13 Fevereiro 2006.

Dr. Eduardo Fernandes Bondan - Rua Caconde 125 / 51 - 01425-011 São Paulo SP - Brasil. E-mail: bondan@uol.com.br. 
ou induzida mediante transplantes gliais deve ser investigada em modelos experimentais. O teste da travessia da passarela (beam walking test) foi previamente utilizado para detectar déficits motores em ratos injetados com BE no funículo dorsal da medula espinhal cervical ${ }^{7}$, revelando nos animais que receberam o gliotóxico uma diminuição da segurança na colocação das patas ao atravessarem a referida passarela, o que não foi mais observado na quinta semana pós-injeção. Os animais injetados com salina exibiam déficits mínimos e rápida recuperação quanto à habilidade de atravessarem a passarela. Quando impedidos de apresenta remre paro das bainhas de mielina pe rdidas pela irradiação das lesões com $40 \mathrm{~Gy}$ de raio $X$, foi observada a incapacidade de os animais recuperarem a função perdida.

Muito embora sejam bastante conhecidos os efeitos ultra-estruturais da injeção experimental do BE no tronco encefálico, com descrição morfológica detalhada do processo de perda e repa ro das bainhas de mielina, o conhecimento exato da repercussão da desmielinização por ele induzida sobre a atividade motora dos animais permanece obscuro. Nesse sentido, é de fundamental importância o estabelecimento de um teste adequado para a detecção de possíveis déficits motores para o modelo no tronco encefálico, servindo como base para estudos futuros e para a avaliação precisa da eficácia de estratégias terapêuticas que visem a reabilitação de indivíduos portadores de áreas desmielinizadas no SNC. A busca de terapias que minimizem os sinais clínicos associados à perda mielínica requer o desenvolvimento de modelos experimentais que mimetizem as condições desmielinizantes de ocorrência natural e a avaliação comp o rtamental e clínica minuciosa das deficiências desencadeadas.

O presente estudo teve como objetivo, assim, investigar a adequação do teste de travessia da passarela7 para a detecção de possíveis déficits locomotores mediante injeção do agente desmielinizante BE na cistema basal do tronco encefálico de ratos Wistar, comparando os resultados encontrados com aqueles obtidos de ratos injetados no mesmo local com solução salina a 0,9\%. Pretendeu-se ainda observar a evolução das prováveis perdas motoras ao longo de dife rentes períodos pós-injeção, a fim de se determinar se existe recuperação funcional significativa no período analisado.

\section{MÉTODO}

Foram utilizados 20 ratos Wistar, machos, de 3 meses de idade ao início do experimento. Tais animais foram tre i- nados para atravessarem uma trave elevada de 2 metros de comprimento e $18 \mathrm{~mm}$ de largura, conforme descrita por Jeff e rye Blakemore ${ }^{7}$, tendo nos dois extremos plataformas de $10 \times 10 \mathrm{~cm}$. O treinamento foi feito mediante uso de recompensa nas duas extremidades, sempre que os animais realizavam a tarefa proposta. A porção central de $1 \mathrm{~m}$ da trave foi medida e seus limites marcados. Cada animal foi treinado individualmente por 5 minutos/dia durante 10 dias, estando o treinamento completo quando cada rato fosse capaz de percorrer com segurança duas vezes a trave elevada nos dois sentidos (ida e volta), sem paradas no meio do caminho e com um mínimo de erros. No décimo dia, foram registradas as travessias (Travessia 1 - ida e volta / Travessia 2 - ida e volta), por observação direta e filmagem, e $n$ t re os limites da porção central da trave por 3 observadores, com atribuição para cada passo dado pelo animal dos seguintes escores ${ }^{7}: 0$ = normal: patas posteriores posicionadas totalmente sobre superfície superior da trave, sem escorregar; 1 = erros menores: presença de escorregões ligeiros de parte da pata posterior entre as superfícies superior e inferior da trave; 2 = erros maiores: presença de escorregões da pata posterior, ultrapassando a superfície ventral da trave.

Cada avaliador atribuiu, então, para cada rato em particular, um escore por passo, relativo à habilidade do animal de realizar a travessia, levando-se em consideração a precisão dos movimentos real izados pelo membro poste rior no lado de observação e podendo-se, assim, analisar ambos os membros na dupla travessia.

No dia seguinte ao último treinamento, os animais foram aleatoriamente divididos em 2 grupos - grupo $E(n=12)$, compreendendo ratos que seriam injetados com $B E$ a $0,1 \%$, e grupo $C(n=8)$, envolvendo os que receberiam solução salina a 0,9\%. Foram anestesiados pela administração intraperitoneal de uma mistura anestésica de 5:1 de cloridrato de quetamina (Ketalar ${ }^{\circledR}$ ) e cloridrato de xilazina (Rompun ${ }^{\circledR}$ ), respectivamente, na dose de $0,1 \mathrm{~mL}$ por $100 \mathrm{~g}$ de peso corporal. Após tricotom ia da região fro n to-parieto-occipital do crânio, foi realizada anti-sepsia cutânea com solução de iodo a $2 \%$ e, a seguir, efetuou-se uma incisão de aproximadamente $5 \mathrm{~mm}$ na pele do crânio, a aproximadamente $1 \mathrm{~cm}$ distal e perpendicular à linha supra-orbital, com exposição e remoção de parte do tecido subcutâneo. Com auxílio de um motor de teto, de uso odontológico, e de uma broca de número 2 , foi feito um orifício na calota óssea a $0,85 \mathrm{~cm}$ póstero-diagonalmente e à direita do bregma até a exposição da dura-máter. Dez micro l i t ros de solução de $\mathrm{BE}$ a $0,1 \%$ em salina a $0,9 \%$ estéril foram injetados na cisterna basal de animais do grupo $E$, enquanto que o mesmo volume de solução salina a $0,9 \%$ foi injetado em animais do grupo C. Para tal, utilizou-se uma seringa de Hamilton de $10 \mu \mathrm{l}$, com agulha removível de calibre 26s, introduzida no orifício previamente feito, numa posição perpendicular ao plano da superfície óssea da calota craniana e em direção à base do crânio. Ao se atingir com a ponta da agulha a base craniana, injetou-se a solução, esperando-se cerca de 10 segundos para a retirada da agulha e com isso perm itindo melhor difusão do líquido pelo sistema cisternal de forma a banhar a ponte.

A pele foi suturada com fio de náilon agulhado 4.0, uti- 
lizando-se pontos simples descontínuos. Os anim ais receberam 2,2 mg/kg de cetoprofeno (Ketofen ${ }^{\circledR}$ ) por via subcutânea para analgesia pós-operatória e, a seguir, foram colocados em caixa contendo maravalha esterilizada por autoclavagem $\left(130^{\circ} \mathrm{C}\right.$ por 20 minutos) e trocada 3 vezes por semana, sendo periodicamente inspecionados para avaliação clínica geral pós-operatória.

Os ratos injetados com EB e salina foram marcados e misturados, a fim de garantir que o tipo de injeção recebida por cada animal fosse desconhecida para os observadores, sendo então tomados de forma aleatória para a execução do teste de avaliação motora.

Três avaliadores foram posicionados do mesmo lado da trave para analisarem a dupla travessia dos animais nos limites considerados de observação e de acordo com os esco res previamente mencionados. A observação foi feita e filmada aos 3, 7, 11, 15, 19, 23, 27, 31 e 35 dias pós-cirurgia. Em cada período avaliado, o observador atribuiu um escore por passo efetuado nas duas travessias completas (duas idas e duas voltas), sendo posteriormente confeccionadas fichas de registro para cada animal analisado.

Com base nas observações efetuadas dos 3 aos 35 dias pós-injeção de BE ou de salina, foram considerados os seguintes parâmetros do comportamento motor dos animais de ambos os grupos:

- Média do número de passos (MNP), na qual tomouse a somatória do número de passos de cada animal por sessão e calculou-se a média do número de passos dos animais do grupo por sessão;

- Média do total de escores (TE), na qual os escores de cada animal foram somados em cada sessão e foi calculada a média do total de escores do grupo por sessão;

- Média do total de escores / núm ero total de passos
(EP), na qual tomou-se o número total de escores de cada animal e dividiu-se pelo respectivo número total de passos por sessão. A partir destes dados, calculou-se a relação número total de passos versus total de escores de cada grupo por sessão.

A seguir, foi realizada análise estatística pelo teste de duas médias com intervalo de confiança de 0,05 ( $z$ crítico $=1,645$ ) dentro do grupo $\mathrm{E}$ (experimental) e $\mathrm{C}$ (controle) para todos os parâmetros da atividade motora (MNP, TE, EP), nos diferentes períodos avaliados em relação à sessão pré-cirurgia, assim como entre os 2 grupos considerados.

Finalmente, realizou-se o processamento das amostras do tronco encefálico, colhidas aos 35 dias pós-inj eção de BE ou salina para observação das lesões induzidas por microscopia de luz e eletrônica de transmissão, a fim de se ce rtificar que todos os animais utilizados em nosso estudo tenham recebido a respectiva injeção no local apropriado e, assim, descartando-se qualquer animal que apresentasse lesão adicional em área originalmente não-prevista. A fim de se obter adequada prese rvação do tecido nervoso, os animais utilizados no experimento foram perfundidos aos 35 dias pós-injeção de BE ou salina, utilizando-se solução de glutaraldeído a $4 \%$ em tampão fosfato de Sorensen 0,1 $\mathrm{M}(\mathrm{pH} 7,2-7,4)$ por via intracardíaca. Fragmentos do tronco encefálico (ponte, mesencéfalo e corpo trapezóide) foram colhidos e pós-fixados com tetróxido de ósmio a $1 \%$, desidratados em série decrescente de acetonas e incluídos em Araldite 502, após estágios transicionais em acetona. Cortes semifinos foram feitos e corados com azul de toluidina a $0,25 \%$. Cortes ultrafinos de áreas selecionadas foram obtidos, corados com acetato de uranila a $2 \%$ e citrato de chumbo e examinados com microscópio eletrônico de transmissão Phillips EM-201.

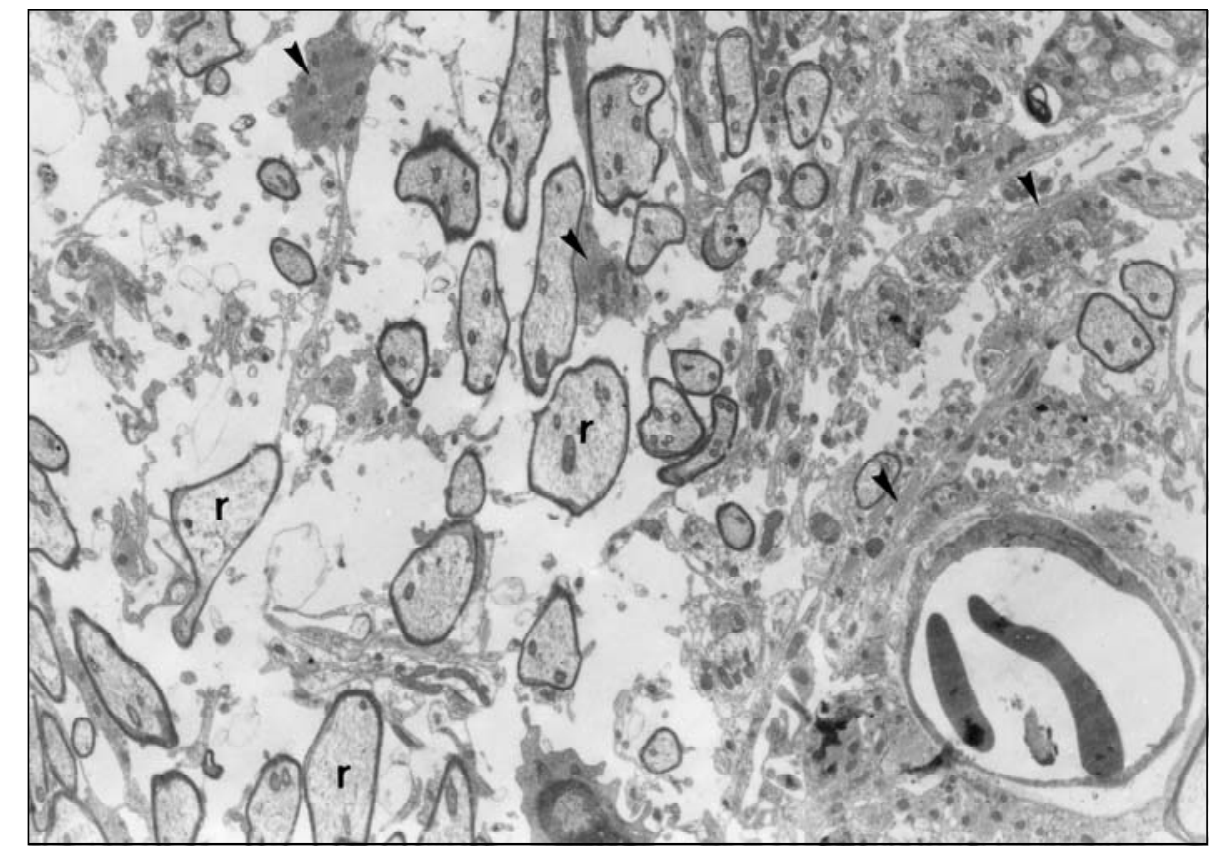

Fig 1. Axônios (r) em processo inicial de remielinização por oligodendrócitos, junto a processos astrocitários (cabeça de seta). 35 dias pós-injeção de BE. Micrografia eletrônica. Barra $=1 \mu \mathrm{m}$. 


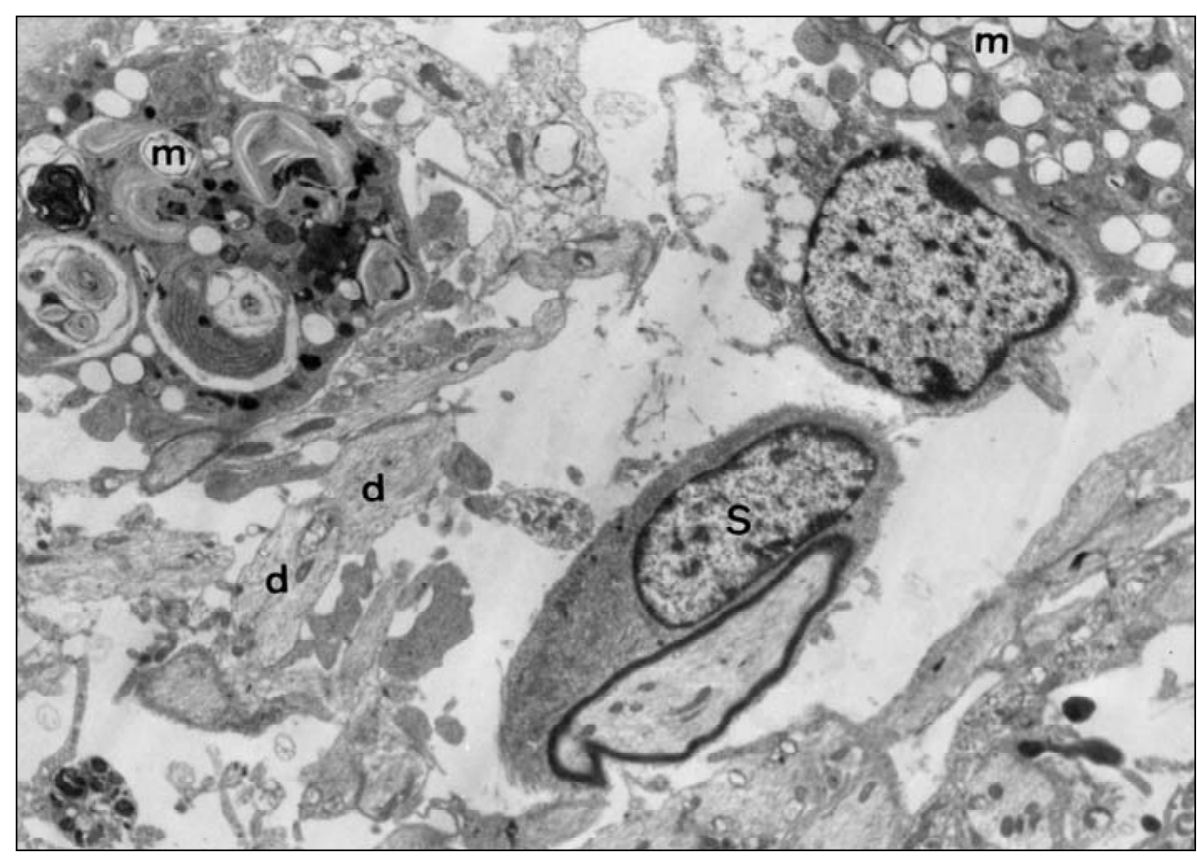

Fig 2. Célula de Schwann (S) em adiantado estado de remielinização, em meio a axônios desmielinizados (d) e macrófagos ativados (m). 35 dias pós-injeção de BE. Micrografia eletrônica. Barra $=1 \mu \mathrm{m}$.

\section{RESULTADOS}

Foram registrados os escores de 12 animais do $\mathrm{g}$ rupo $\mathrm{E}$ e 8 do grupo $\mathrm{C}$. Os resultados foram obtidos mediante observação das fitas de filmagem, uma vez que os 3 observadores consideraram bastante difícil a atribuição de escores apenas pela observação direta das travessias, dada a rapidez de movimentos de alguns animais.

À microscopia de luz, as lesões induzidas pelo BE aos 35 dias apresentaram extensão variável ao longo da ponte, onde às vezes chegavam a comprometer $1 / 3$ dela ventralmente, em proximidade às meninges. Quanto aos animais injetados com salina, em apenas 2 (de 8 analisados) foram identificadas diminutas lesões pontinas aos 35 dias pós-injeção, resultantes do trauma da injeção.

A maior extensão das lesões nos animais injetados com BE foi atribuída à ação gliotóxica da droga, com indução de desmielinização primária nos feixes nervosos pontinos. Nos animais analisados de ambos os $\mathrm{g}$ rupos, não houve qualquer evidência de lesão em áreas não previstas originalmente no projeto, tais como cerebelo e mesencéfalo. Os aspectos ultra-estruturais das lesões induzidas pela administração de BE ou salina no tronco encefálico aos 35 dias pós-injeção foram documentados pela obtenção de miorografias eletrônicas. $O$ estudo ultra-estrutural revelou, em apenas 1 dos animais injetados com solução salina, leve edema periaxonal, sem, no entanto, qualquer evidência de perda de células da macróglia e desmielinização primária e/ou secundária. Nos animais injetados com $B E$, foi possível identificar distintos aspectos da lesão em relação a sua topografia (central e periférica) aos 35 dias pós-injeção, bem como a respectiva localização do processo remielinizante executado pelas células mielinogênicas. $O$ reparo foi visto sob a forma de duas distintas áreas de remielinização, uma por oligodendrócitos e exibindo finas bainhas ao redor dos axônios (Fig 1), com freqüente presença de processos astrocitários hipertróficos; outra remielinizada por células de Schwann invasivas, em estágios iniciais de associação com axônios ainda despro vid os de mielina ou já em adiantado processo de reconst rução das bainhas (Fig 2). As células de Schwann situavam-se em áreas de espaço extracelular expandido, onde ainda persistiam restos mielínicos, alguns axônios ainda desmielinizados e macrófagos contendo mielina em diferentes estágios de degradação, desde a visualização de lamelas até glóbulos de gordura neutra.

$\mathrm{Na}$ área central da lesão, persistiam axônios desnudos, isoladamente ou em grupos, entremeados com redes desorganizadas de membranas derivadas de mielina e muitos macrófagos ativados (Fig 3).

Foi realizada análise estatística pelo teste de duas médias com intervalo de confiança de 0,05 ( $z$ crítico 


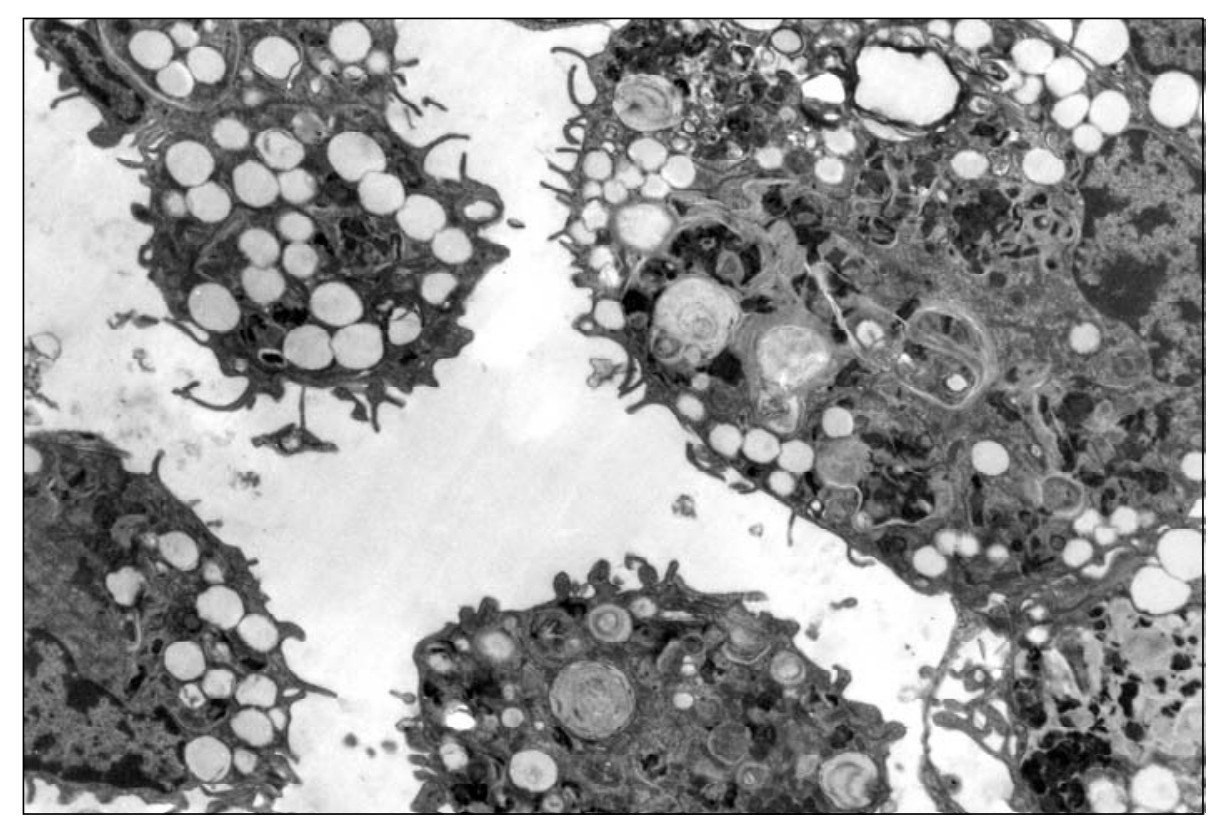

Fig 3. Detalhe da área central da lesão contendo macrófagos em distintos estágios de degradação mielínica. 35 dias pós-injeção de BE. Micrografia eletrônica. Barra = $1 \mu \mathrm{m}$.

Tabela 1. Efeitos da injeção intracisternal do gliotóxico BE na atividade motora de ratos observados na trave elevada por 35 dias.

\begin{tabular}{cccc}
\hline Sessões & MNP & TE & EP \\
\hline Pré-cirurgia & $26,58 \pm 0,51$ & $4,91 \pm 1,50$ & $0,18 \pm 0,05$ \\
3 & $20,67 \pm 2,81^{*}$ & $21,66 \pm 4,45^{*}$ & $0,99 \pm 0,12^{*}$ \\
7 & $18,83 \pm 3,09^{*}$ & $20,37 \pm 3,64^{*}$ & $1,21 \pm 0,12^{*}$ \\
11 & $24,58 \pm 2,24^{*}$ & $12,19 \pm 1,58^{*}$ & $0,61 \pm 0,13^{*}$ \\
15 & $25,83 \pm 2,82$ & $10,59 \pm 1,70^{*}$ & $0,53 \pm 0,14^{*}$ \\
19 & $26,00 \pm 2,17$ & $10,46 \pm 0,91^{*}$ & $0,56 \pm 0,07^{*}$ \\
23 & $27,33 \pm 1,30$ & $9,21 \pm 1,13^{*}$ & $0,34 \pm 0,05^{*}$ \\
27 & $26,10 \pm 2,47$ & $7,95 \pm 1,30^{*}$ & $0,44 \pm 0,14^{*}$ \\
31 & $25,17 \pm 2,24$ & $9,87 \pm 1,93^{*}$ & $0,53 \pm 0,15^{*}$ \\
35 & $25,67 \pm 2,48$ & $5,29 \pm 1,53$ & $0,52 \pm 0,15^{*}$ \\
\hline
\end{tabular}

* $\mathrm{P}<0,05$ em relação à sessão pré-cirurgia. $M N P$, média do número de passos; $T E$, média do total de escores; EP, média do total de escores / número total de passos.

$=1,645$ ) dentro do grupo $\mathrm{E}$ (injetado com BE) e C (injetado com salina) para todos os parâmetros da atividade motora (MNP, TE, EP), nos diferentes períodos avaliados em relação à sessão pré-ciru rgia, assim como entre os 2 grupos considerados.

Os resultados observados nos grupos E e C são apresentados, respectivamente, nas Tabelas 1 e 2. A Tabela 3 compara os resultados encontrados para os 3 parâmetros motores, dos 3 aos 35 dias pós-injeção intracisternal, entre os grupos E e C.
Nos animais injetados com $B E$, observou-se que, em relação à sessão pré-ciru rgia, o parâmetro MNP foi significantemente menor dos 3 aos 11 dias; a TE, maior dos 3 aos 31 dias; e a EP, maior dos 3 aos 35 dias pós-injeção.

Já nos animais injetados com salina, constatou-se que o parâmetro MNP foi estatisticamente menor aos 11 dias e maior dos 19 aos 31 dias em relação à sessão pré-cirurgia. Por outro lado, a TE foi significantemente maior dos 3 aos 11 dias e a EP, maior dos 
Tabela 2. Efeitos da injeção intracisternal de solução salina na atividade motora de ratos observados na trave elevada por 35 dias.

\begin{tabular}{cccc}
\hline Sessões & MNP & TE & EP \\
\hline Pré-cirurgia & $27,50 \pm 0,46$ & $4,88 \pm 0,25$ & $0,18 \pm 0,01$ \\
3 & $27,50 \pm 0,16$ & $17,09 \pm 0,64^{*}$ & $0,61 \pm 0,02 *$ \\
7 & $27,63 \pm 0,18$ & $11,54 \pm 0,88^{*}$ & $0,41 \pm 0,03^{*}$ \\
11 & $26,88 \pm 0,58^{*}$ & $5,76 \pm 0,41^{*}$ & $0,21 \pm 0,02^{*}$ \\
15 & $27,88 \pm 0,51$ & $4,81 \pm 0,20$ & $0,17 \pm 0,01 *$ \\
19 & $29,13 \pm 0,64^{*}$ & $5,41 \pm 0,42$ & $0,19 \pm 0,02$ \\
23 & $28,25 \pm 0,16 *$ & $4,41 \pm 0,35$ & $0,15 \pm 0,01 *$ \\
27 & $29,38 \pm 0,38^{*}$ & $3,59 \pm 0,17$ & $0,12 \pm 0,01$ * \\
31 & $28,13 \pm 0,40^{*}$ & $5,14 \pm 0,67$ & $0,18 \pm 0,02$ \\
35 & $27,75 \pm 0,41$ & $5,10 \pm 0,68$ & $0,18 \pm 0,02$ \\
\hline * P<0,05 em relação à sessão pré-cirurgia. MNP, média do número de passos; TE, média
\end{tabular}

do total de escores; EP, média do total de escores / número de total de passos.

Tabela 3. Comparação entre as observações relativas aos parâmetros motores no grupo $E$ (experimental) em relação ao C (controle) durante a travessia da trave elevada por 35 dias.

\begin{tabular}{ccccccc}
\hline Sessões & \multicolumn{2}{c}{ MNP } & \multicolumn{2}{c}{ TE } & \multicolumn{2}{c}{ EP } \\
& Grupo E & Grupo $C$ & Grupo $E$ & Grupo $C$ & Grupo E & Grupo C \\
\hline Pré-cirurgia & $26,58 \pm 0,51$ & $27,5 \pm 0,46$ & $4,91 \pm 1,50$ & $4,88 \pm 0,25$ & $0,38 \pm 0,05$ & $0,18 \pm 0,01$ \\
3 & $20,67 \pm 2,81^{*}$ & $27,50 \pm 0,16$ & $21,66 \pm 4,45^{*}$ & $17,09 \pm 0,64$ & $0,99 \pm 0,12^{*}$ & $0,61 \pm 0,02$ \\
7 & $18,83 \pm 3,09^{*}$ & $27,63 \pm 0,18$ & $20,37 \pm 3,64^{*}$ & $11,54 \pm 0,88$ & $1,21 \pm 0,12^{*}$ & $0,41 \pm 0,03$ \\
11 & $24,58 \pm 2,24^{*}$ & $26,88 \pm 0,58$ & $12,19 \pm 1,58^{*}$ & $5,76 \pm 0,41$ & $0,61 \pm 0,13^{*}$ & $0,21 \pm 0,02$ \\
15 & $25,83 \pm 2,82^{*}$ & $27,88 \pm 0,51$ & $10,59 \pm 1,70^{*}$ & $4,81 \pm 0,20$ & $0,53 \pm 0,14^{*}$ & $0,17 \pm 0,01$ \\
19 & $26,00 \pm 2,17^{*}$ & $29,13 \pm 0,64$ & $10,46 \pm 0,91^{*}$ & $5,41 \pm 0,42$ & $0,56 \pm 0,07 *$ & $0,19 \pm 0,02$ \\
23 & $27,33 \pm 1,30^{*}$ & $28,25 \pm 0,16$ & $9,21 \pm 1,13^{*}$ & $4,41 \pm 0,35$ & $0,34 \pm 0,05^{*}$ & $0,15 \pm 0,01$ \\
27 & $26,10 \pm 2,47^{*}$ & $29,38 \pm 0,38$ & $7,95 \pm 1,30^{*}$ & $3,59 \pm 0,17$ & $0,44 \pm 0,14^{*}$ & $0,12 \pm 0,01$ \\
31 & $25,17 \pm 2,24^{*}$ & $28,13 \pm 0,40$ & $9,87 \pm 1,93^{*}$ & $5,14 \pm 0,67$ & $0,53 \pm 0,15^{*}$ & $0,18 \pm 0,02$ \\
35 & $25,67 \pm 2,48^{*}$ & $27,75 \pm 0,41$ & $5,29 \pm 1,53$ & $5,10 \pm 0,68$ & $0,52 \pm 0,15^{*}$ & $0,18 \pm 0,02$ \\
\hline
\end{tabular}

* $\mathrm{P}<0,05$ em relação ao grupo controle (C). MNP, média do número de passos; TE, média do total de escores; EP, média do total de escores / número de total de passos.

3 aos 11 dias e menor no $15^{\circ}, 23^{\circ}$ e $27^{\circ}$ dias em relação à pré-cirurgia.

Pelo teste de duas médias, observou-se diferença significante entre as MNPs dos 2 grupos, sendo sempre maior no $\mathrm{C}$ em relação ao grupo $\mathrm{E}$, com exceção das sessões pré-cirurgia.

Com relação à $T E$, verificou-se que os totais de erros cometidos durante a travessia foram significantemente maiores nos animais injetados com BE que nos com salina, excetuando-se na sessão pré-cirúrgica e aos 35 dias de observação.
Por fim, o parâmetro EP apresentou resultados significantemente maiores no grupo E dos 3 aos 35 dias pós-injeção intracisternal de $\mathrm{BE}$, em comparação àqueles verificados nos animais do grupo $C$.

\section{DISCUSSÃO}

No presente estudo, o BE foi selecionado como agente desmielinizante, uma vez que sua ação é re$t$ a rdada em relação ao momento da injeção, perm itindo, portanto, clara separação entre os efeitos do 
trauma inerente ao procedimento cirúrgico de acesso ao SNC e os efeitos da perda mielínica isoladamente. Sabe-se que tal agente mostra-se capaz de exercer seus efeitos gliotóxicos sobre oligodendrócitos e astrócitos p refe rencialmente dos 3 aos 7 dias pós-injeção, com conseqüente desmielinização e ruptura da membrana limitante glial e da barreira hematoencefálica ${ }^{3,4}$.

Os resultados sugerem que, muito embora o procedimento cirúrgico de injeção intracisternal tenha sido capaz de prejudicar o desempenho motor dos 3 aos 11 dias pós-ciru rgia (como evidenciado quanto ao parâmetro TE) nos ratos injetados com salina, a injeção do gliotóxico re presentou um prejuízo adicional na atividade motora de travessia da trave elevada nos animais do grupo E dos 3 aos 31 dias, ao se comparar os 2 grupos quanto aos valores de TE por período ou sessão considerada.

A observação de prejuízo motor nos animais do g rupo $E$ até os 31 dias, mas não mais aos 35 dias, é consistente com os achados ultra-estruturais de trabalhos anteriores ${ }^{8-10}$, que mostram progressiva redução da resposta inflamatória induzida pelo gliotóxico a partir do $11^{\circ}$ dia e o início de um processo remielinizante crescente efetuado por oligodendrócitos sobreviventes e por células de Schwann invasivas a partir do $15^{\circ}$ dia pós-injeção. Os achados ultra-estruturais descritos no presente trabalho mostram claramente a existência de tentativas de reparo mielínico na periferia das lesões induzidas pelo $\mathrm{BE}$, apesar da presença de muitos axônios ainda desmielinizados na área central delas. Esta remielinização ainda incompleta aos 35 dias mostrou-se já eficiente no sentido de recuperar a habilidade motora dos animais de atravessar a trave elevada com um número de erros similar ao do período pré-lesional.

A média do número de passos foi significantemente menor dos 3 aos 11 dias pós-injeção do gliotóxico, provavelmente pela dificuldade de locomoção e pela falta de segurança nos passos que os animais experimentavam durante a travessia, como resultado da perda oligodendroglial e, conseqüentemente, mielínica induzida pelo BE neste período. Por sua vez, o aumento da MNP nos animais do grupo $C$ requer um estudo mais detalhado para que possa ser melhor compreendido, podendo talvez ser atribuído a uma facilitação motora decorrente de um processo de a p rendizado. Como verificado em estudos prévios ${ }^{8-}$ 10, a lesão induzida pelo trauma cirúrgico e pela injeção da solução salina mostrou-se mínima, sem evidência de perda de células da neuróglia e de perda mielínica.
Observou-se também que a MNP nos animais do grupo $E$ foi sempre significantemente inferior daquela encontrada no grupo $C$ para cada período analisado.

Os resultados da evolução da média do total de escores / número de total de passos, embora sempre significantemente superiores nos animais injetados com $\mathrm{BE}$ em relação àqueles injetados com salina, mostram-se de interpretação mais complexa, já que embutem as alterações observadas nos parâmetros MNP e TE em cada período analisado.

A presente investigação permite comprovar a existência de um claro prejuízo motor determinado pelas lesões desmielinizantes induzidas pelo $\mathrm{BE}$, mostrando que o teste da travessia da passare $\mathrm{I}^{7}$ se mostra bastante adequado para a detecção dos déficits motores gerados pelo gliotóxico no tronco encefálico, ao mesmo tempo que permite correlacionar o processo remielinizante subseqüente com a aparente recupera ção funcional demonstrada a partir dos 31 dias.

À semelhança dos resultados de Bondan e col.8-10, a remielinização por células de Schwann, embora p resente em áreas subpiais e perivasculares como encontrado na medula espinhal ${ }^{4}$ e no tronco encefáli$\mathrm{CO}^{1}$, não se mostrou aos 35 dias confinada a tais locais, sugerindo não haver topografia específica de fibras ne nosas remielinizadas por oligodendrócitos ou por células de Schwann, a não ser pela constatação de que as últimas estavam presentes em locais de espaço extracelular aumentado, o que facilitaria sua infiltração e movimentação a partir do sistema nervoso periferico SNP. Ainda, ao contrário do constatado na medula espinhal ${ }^{4}$, a remielinização de origem oligodendroglial mostrou-se quantitativamente mais importante no tronco encefálico aos 35 dias pós-injeção do BE do que a efetuada por células de Schwann, conformejá descrito por Yajima e Suzuki', Reynolds e Wilkin ${ }^{6}$ e por Bondan e cols8-10, ocorrendo na periferia da área lesada, onde havia diminuição do abundante infiltrado macrofágico observado no centro lesional.

A constatação da maior velocidade de produção de mielina pelas células de Schwann em relação à dos oligodendrócitos, bem como a vigorosa reação ast rocitária marginal foram também descritas em trabalhos anteriores envolvendo o gliotóxico ${ }^{1-6,8-10}$. Nesta reação, os processos astrocitários mostraram-se espessados e preenchidos por abundantes e uniformes feixes de filamentos gliais, além de apresentarem-se dispostos por entre axônios preservados, remielinizados ou não, em padrão sugestivo de gliose isomórfica. 
Dessa forma, o teste da travessia da trave elevada mostrou-se capaz de demonstrar a geração de déficits locomotores decorrentes do processo desmielinizante acarretado pelo $\mathrm{BE}$, sobrepondo-se ao prejuízo motor determinado pelo simples trauma cirúrgico de acesso ao SNC. O estudo permitiu ainda constatar que existe uma recuperação progressiva da função motora à medida que se desenvolve o processo de remielinização efetuado pelos oligodendrócitos sobreviventes e pelas células de Schwann invasivas nas margens do foco de lesão induzido pelo BE.

Embora déficits comportamentais tenham sido mensurados em animais afetados por encefalomielite alérgica experimental (EAE), sabe-se que os efeitos encontrados nesta doença são atribuíveis não apenas à desmielinização, mas também à inflamação ${ }^{17}$. Dessa fo rma, é importante a descrição de um modelo mais p reciso de avaliação das conseqüências funcionais da perda mielínica primária, envolvendo uma zona desmielinizada mais claramente delimitada, como aquela induzida pela injeção local de BE.

Os efeitos funcionais de uma zona localizada de desmielinização e remielinização podem ser potencialmente detectados pela mensuração de parâmetros eletrofisiológicos e comportamentais. A avaliação eletrofisiológica da condução central durante desmielinização induzida pela lisolecitina e posterior remie linização do funículo dorsal da medula espinhal do gato forneceu clara evidência de que o bloqueio de condução ocorre durante a perda mielínica e que desaparece com o re pa roespontâneo subseqüente ${ }^{18,19}$.

A remielinização central por células de Schwann tem mostrado ser eficaz no restauro da função, de forma idêntica àquela efetuada por oligodendrócitos na lesão desmielinizante induzida pela lisolecitina ${ }^{20}$. Recentemente, transplantes gliais em ratos mielinodeficientes revelaram melhorar a velocidade de condução a valores aproximados aos de ratos norm a i $\mathrm{s}^{15}$ e transplantes envolvendo células de Schwann puderam restabelecer a condução normal a axônios previamente desmielinizados com $\mathrm{BE}^{16}$. Em contraste, os efeitos comportamentais de zonas de desmielinização e remielinização em sujeitos experimentais têm recebido pouca atenção, embora os sinais clínicos de inúmeras doenças desmielinizantes sejam sempre atribuídos à perda mielínica de axônios centrais. Nesse contexto, é importante que os efeitos motores da perda e reparo mielínico sejam investigados, uma vez que a demonstração de que a integridade eletrofisio- lógica foi recuperada não necessariamente implica que a função motora normal irá retornar.

\section{REFERÊNCIAS}

1. Yajima K, Suzuki K. Ultrastructural changes of oligodend roglia and myelin sheaths induced by ethidium bromide. Neuropath Appl Neurobiol 1979;5:49-62.

2. Yajima K, Suzuki K. Demyelination and remyelination in the rat nervous system following ethidium bromide injection. Lab Invest 1979;41:385-392.

3. Blakemore W F. Ethidium bromide induced demyelination in the spinal cord of the cat. Neuropath Appl Neurobiol 1982;8:365-375.

4. Graça D L, Blakemore W F. Delayed remyelination in the rat spinal cord following ethidium bromide injection. Neuropath Appl Neurobiol 1986;12:593-605.

5. Gilson J, Blakemore WF. Failure of remyelination in areas of demyelination produced in the spinal cord of old rats. Neuropath Appl Neurobiol 1993;19:173-181.

6. Reynolds R, Wilkin G P. Cellular reaction to an acute demyelinating / remyelinating lesion of the rat brain stem: localization of GD3 ganglioside immunoreactivity. J Neurosc Res 1993;36:405-422.

7. Jeffery N D, Blakmeore W F. Locomotor deficits induced by experimental spinal cord demyelination are abolished by spontaneous remyelination. Brain 1997;120:27-37.

8. Bondan E F, Lallo M A, Sinhorini I L, Graça D L. Schwann cells may express an oligodendrocyte-like remyelinating pattern following ethidium bromide injection in the rat brainstem. Acta Microscopica 1999;8:707-708

9. Bondan E F, Lallo M A, Sinhorini I L, Baz E I, Paulino C A, Graça D L. Ultrastructural investigation on the brainstem remyelination after local ethidium bromide injection in rats immunosuppressed with dexamethasone. Acta Microscopica 1999;8:709-710.

10. Bondan E F, Sinhorini I L, Lallo M A, Graça D L. The effect of cyclophosphamide on the rat brainstem remyelination following local ethidium bromide injection in Wistar rats. J Submicrosc Cytol Pathol 2000;32:603-612.

11. Bondan E F, Lallo M A, Pereira L A V D, Sinhorini I L, Graça D L. Behaviour of invading Schwann cells in the ethidium-bromide-induced lesions in the brainstem of streptozotocin diabetic rats. Acta Microscopica 2001;8:41-42.

12. Bondan E F, Lallo M A, Dagli M L Z, Pereira L A V D, Graça D L. Ruptura da barreira hematoencefálica após injeção de droga gliotóxica no tronco encefálico de ratos Wistar. Arq Neuropsiquiatr 2002;60:582-589.

13. Bondan E F, Lallo M A, Dagli M L Z, Sanchez M, Graça D L. Estudo da imunorreatividade astrocitária para GFAP e Vimentina no tronco encefálico de ratos Wistar submetidos ao modelo gliotóxico do brometo de etídio. Arq Neuropsiquiatr 2003;61:642-649.

14. Bondan E F, Lallo M A, Baz E I, Sinhorini I L, Graça D L. Estudo ultraestrutural do processo remielinizante pós-injeção de brometo de etídio no tronco encefálico de ratos imunossuprimidos com dexametasona. Arq Neuropsiquiatr 2004;62:131-138.

15. Utzschneider D A, Archer D R, Kocsis J D, Waxman S G, Duncan I D. Transplantation of glial cells enhances action potential conduction of amyelinated spinal cord axons in the myelindeficient rat. Proc Natl Acad Sci USA 1994;91:53-57.

16. Honmou O, Felts P A, Waxman S G, Kocsis J D. Restoration of normal conduction properties in demyelinated spinal cord axons in the rat by transplantation of exogenous Schwann cells. J Neurosc 1996;16:3199-3208.

17. Matthaei I, Polman C H, de Groot C J A, Dijkstra C D, Koetsier J C, Sminia T. Observer agreement in the assessment of clinical signs in experimental allergic encephalomyelitis. J Neuroimmunol 1989;23:25-28.

18. Smith K J, Blakemore W F, McDonald W I. Central remyelination restores secure conduction. Nature 1979;280:395-396.

19. Smith K J, Blakemore W F, McDonald W I. The restoration of conduction by central remyelination. Brain 1981;104:383-404.

20. Fetls PA, Smith KJ. Conduction propeties of central never fiber remyelinated by Schwann cells. Brain Res 1992;574;178-192. 